\title{
The Development of Arithmetic Gamification Using Digital Dice
}

\author{
Suprih Widodo $^{1 *}$, Puji Rahayu ${ }^{1}$, Nahrowi Adjie ${ }^{1}$, Sri Adi Widodo ${ }^{2}$, Bayu Rahmat Setiadi ${ }^{3}$ \\ ${ }^{1}$ UPI Kampus Purwakarta, Universitas Pendidikan Indonesia, Purwakarta, Indonesia \\ ${ }^{2}$ Mathematics Education, Universitas Sarjanwiyata Tamansiswa, Yogyakarta, Indonesia \\ ${ }^{3}$ Mechanical Engineering Education, Universitas Sarjanawiyata Tamansiswa, Yogyakarta, Indonesia \\ *Corresponding author E-mail: supri@upi.edu
}

\begin{abstract}
Due to the importance of arithmetic abilities for elementary school students, this research aims to develop games using digital dice.This games will be used in gamification in math education. This research method is research and development, while the game development process using the waterfall model of system development life cycle. Based on the results of development, the system is built so that the students are emotionally engaged through digital dice games, they didn't only tap the screen or answer the exercise. The resu lts of functional testing and compatibility also show that the system has excellent functionality and compatibility.
\end{abstract}

Keywords: gamification, arithmetic, dice

\section{Introduction}

The ability of arithmetic is a very important ability for elementary school students because the application is mostly found in everyday life. Arithmetic ability will support the success of learning other mathematical concepts because almost all the mathematical concepts to be studied in the next level will be closely related. Arithmetic owes its important position in the school curriculum to two reasons. First, it teaches certain fundamental facts and processes which everyone must use; secondly, it offers a mental drill that is more complete, more definite, and more insistent than any other branch taught in the secondary schools [1].

The specific issue in this study is based on interviews with a number of teachers in some elementary schools in Purwakarta Indonesia in $2014,2015,2016$, that students have difficulty in learning mathematics because they have difficulty in learning arithmetic, especially multiplication.

To be able to understand and like mathematics which is abstract, the process of learning mathematics, especially the subject matter of the concept counting operations should be delivered in a meaningful and fun ways and must be able to show the benefits of mathematics in solving various problems in life. In addition, the involvement of students and the presentation of interesting learning is an effort by the teacher. One alternative is to apply the gamification in mathematics. This is in line with the age of development of elementary school students who are in concrete operational stage and love the game [2]. Furthermore, the key to learning arithmetic is through meaningful experience and practical application. These computing skills need to can be nurtured by a variety of systematic practices and exercises [3]. Through the game, students will truly engage, do not feel compelled and afraid. However, some existing arithmetic games have not followed the technological change that grew rapidly. As in [4] uses cards and game boards to teach the notion of adding a high level of cognitive skills (reasoning and strategy). Another game research is the use of personal computer-based monkey tales that compare students' arithmetic skills based on learning with the game with regular practice. [5][6][7]. In the other hand, the use of the Android-based smartphone is a huge number of users in the world, in 2018 dominate the market by $85,9 \%$ [8]. Preliminary analysis in this study shows that the number of arithmetic games in the Android Play store is as much as multiple choice game. Students answer a random question set by the system and choose the right answers to have a score. Then the students choose the level of the game with some reward. There are only 2 games found that are "mental arithmetic" and "Buddy school" which use the fun game elements in their application.

This research aims to develops "Bee Math and Bingo math $\mathrm{X}$ and +", as an android based application that can be played by anyone, anytime and anywhere. And the purpose is to improve the arithmetic skill of primary school students using digital dice. It is based on, the effort that has been made by the students focus back on learning after spending time and energy just to play games like angry birds [9]. So the elements in the game can be utilized for tasks, and exploit human nature in terms of student motivation and involvement.

The term of gamification refers to the use of game elements or game thinking in a non-game context in order to increase engagement between students and learning application [10]. Gamification is important in learning, because today students are, a $\mathrm{Z}$ generation that fluent in technology. As in [11] they are individuals with new and growing characteristics of digital technology that make their learning styles different from students' learning styles in previous generations.

It has been proven that games are so rapidly growing, downloaded and played by students and addictive. And gamification in math education also arises such as [12][13]. This research develops games that previously done manually, into digital games that can be done anytime and anywhere in the context of improving the ability in arithmetic, especially multiplication and addition with the concept of gamification. 
To use gamification in education, the step according to [14] is as shown in Fig. 1.

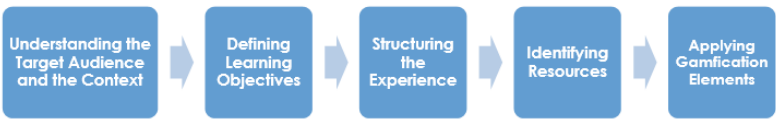

Fig. 1: The use of gamification in education

A good understanding of who the audience is, in combination with the context in which the program will be delivered will help in designing programs that empower students to achieve program objectives. Audience analysis should be done to know factors such as the age group, learning ability, current skills, and so on.

Learning process must have a goal to be achieved by the students at the end of the program. Goals may include understanding students' concepts, performing tasks after training, or completing a learning program. Experience structure can be a milestone. Stages and milestones are powerful tools that enable teachers to rank knowledge and measure what students need to learn and accomplish at the end of each stage or milestone.

\section{Methods}

This research is part of a research development on the Eligibility phase of media experts and material experts, as well as limited trials. This type of research is a qualitative research which is conducted in the even semester of academic year 2017/2018. The media expert Eligibility tester is Prof. Dr. Abdul Ghofur, M.Sc. and material experts namely Prof. Dr. Suhardi, M.Pd, both experts are from Yogyakarta State University. As for the limited test is conducted in the educational program of primary school teachers in Sarjanawiyata Tamansiswa University of Yogyakarta. In the limited test phase conducted in $4 \mathrm{H}$ class with the number of 30 students and Octavian Muning Sayekti, M.Pd. as a lecturer Indonesian language skills subjects.

This study focuses on the assessment of the Eligibility of interactive multimedia skills of Indonesian language by media experts, material experts and users both lecturers and students. Data is taken through questionnaires, interviews, and documentation. Data were analyzed descriptively qualitative. The data analysis consists of three simultaneous activity flow, data reduction, data presentation, and conclusion or verification [18].

This research is a research development, so that research method used is research method of development of R $\mathrm{n} D$. Research and development (R \& D) according to [15] is an industry-based development model in which the systems are tested, evaluated and refined until they meet the specified criteria of effectiveness, quality, or similar standards.

This research designed with the $\mathrm{R} \& \mathrm{D}$ approach, as in [15] refers to a process used develop and validate educational products. This understanding implies that the method of research and development in the field of education in principle is a process to develop a product research, and further validate the product. This means that research and development methods are applied to produce the product and test the effectiveness of the product. In the context of this study, the research product to be developed and validated is an Android-based game application, the arithmetic multiplication model for primary school students.

The procedures in this study are in accordance with the approach as in research and development (R \& D), [15][16]. The research procedures covered ten activity including (1) limited survey and information gathering, (2) planning, (3) ) develops preliminary form of product design, (4) conducts preliminary field testing, (5) main product revision, (6) conducts main product field testing (main field testing, 7) product revision, (8) conducting operational field testing, (9) refining the model to develop the final product revision, and (10) dissemination and distribution.

This research is the first stage of product development using the software engineering approach. To ensure the quality of application development, the method to implement "Bingo Math
$\mathrm{X}$ and Bee Math X" gamification will follow waterfall model of the software development lifecycle (SDLC). SDLC waterfall model is a fairly classic approach, but still can be used by software developers. the software development steps waterfall model shown in the fig. 2

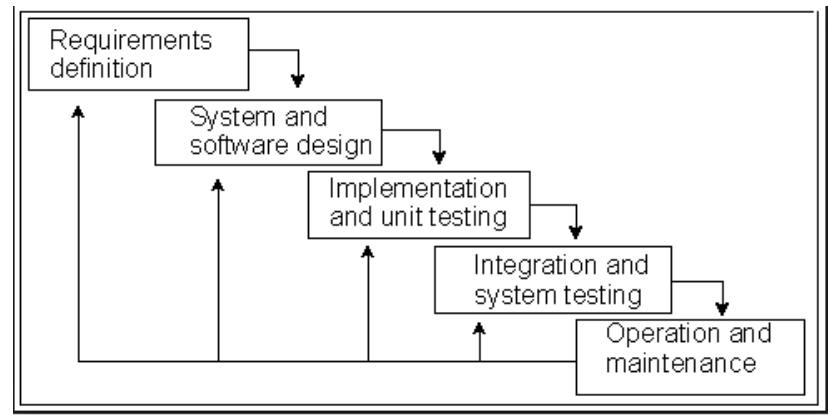

Fig. 2: SDLC Waterfall Model

According to [17] these steps including:

- Requirement definition or system requirement specification stage is the analysis of system requirements created in a form that can be understood by the client and the developer staff. At this stage, the client or user explains all the constraints and objectives and defines what the system wants. Once the specification document is approved then the document becomes a contract of work between the client and the developer.

- The next stage is the design, at this stage, the developer will produce a system architecture as a whole, this stage determines the flow of software to the detailed phase algorithm.

- The next stage of implementation, the stage where the entire design is converted into program codes. the resulting program code is still in the form of modules which will then be integrated into a complete system to ensure that the software requirements have been met.

- The next stage is verification by the client, the client test whether the system has been in accordance with the contract that has been approved.

- The final stage is maintenance which includes installation and process of system improvement according to contract

In designing this arithmetic game, the author refers to the 8 principles of gamification production including conceptual challenges; productive failure; carefully calibration; Boost Persistence; builds confidence; enhances intrinsic motivation; accessibility; and deeper learning [18].

Conceptual challenges built through this game is for students to do drill and practice. The arithmetic game is the arithmetic game of addition and multiplication. Both games are designed with the same design, only the operating algorithm is changed. In this game, students have the role in determining the problems that will arise in the game.

The game will use the dice as a distinguishing element with other android based games. In this game, dice is chosen because it is very closely related to the development of mathematics, especially Galileo Galilei's 1956 probability theory. A student has the role to determine the question by shaking the dice.

The recommended device to be used is a touchscreen phone with a maximum of 6-inch screen or a handheld device with one hand only. This is because students have to shake the device as well as shaking dice. There are two games to be built: "Bingo Math X and BeeM Math X". Both are given the suffix $\mathrm{x}$ and + as the meaning of the operation to be played in the game.

The productive failure and enhances of intrinsic motivation built into this game do not have a heavy impact on students, just messages that answer students wrong and reduce their early life. Feedback in the form of rewards and bonuses given to students if their answers are correct. By providing this feedback students are expected to be motivated to quickly complete the game at a low level to the harder level. The highest scoring recording is also a 
reward for students in this game. Scoring is based on the remaining time of student's correct answer.

Careful calibration in this system is implemented through the level of the difficulty level of problems given to students, especially in a game "Bingo Math X". Zone proximal development in learning mathematics through this game will divide the students into their respective zones so that teachers can provide follow-up, with the view the history of students' arithmetic abilities through the game boards.

Boost persistence and Builds confidence in this game are in the form of providing the simplest game at the lowest level so that students are expected to keep playing despite failing to complete the game board several times. The emergence of the dice to complement the game board may be somewhat frustrating, but with a predetermined algorithm, the probability of dice numbers to emerge will be magnified with a special algorithm.

This game is not supported by learning materials and resources. Therefore in general accessibility and deeper learning in this game is limited through different game levels. Each student who has not successfully completed the low level is not recommended to open the next level. this is done by locking the harder level. The levels in the game indicate the difficulty of arithmetic operations

\section{Result and Discussion}

Bingo math $\mathrm{X}$ and BeeM Math $\mathrm{X}$, using two digital dice that will determine the question of multiplication to be answered by the student. Digital dice is used as questions determined by students based on shuffling results. The developed digital dice is a touch screen mobile-only app that does not use touch gestures like digital dice applications that are plentiful on the android play store. This the author considers as the game's appeal that found earlier in the Samsung SCH-S310 and Omnia mobile phone applications. At the first level of "Bingo Math X game", students will play dice numbers $1-6$, so the game domain will be at the numbers $1-36$. The game begins with a game board displaying the multiplication board of 1-36. Students must shake the dice, then the two dice number shown will be the questions that must be answered in 10 seconds. If the student successfully answers correctly, then the game board showing the multiplication number will change color. If the student fails to answer the game board does not change, but will reduce the lives of the 5 lives given at the beginning of the game. The game at this level will end after the students answer all the chances of the emergence of the 2 of 6 dice number.

In general, "BeeM Math X" game is almost the same as "Bingo Math X", in which students play with two digital dice to be shaken. A problem will be given according to the dice number that appears. The fundamental difference lies in the game board. "BeeM Math X" game uses a honeycomb pattern as a board game. The level of the game is also based on the use of dice. The highest level of the game is level 4, which is when the game uses 15-to-20 number of dice. The bonus score on "Beem Math X", viewed based on horizontal, vertical and diagonal line pattern of 3 hexagon pieces.

\section{Requirement and Architecture System}

The general system requirement analysis of these two arithmetic games is: digital dice rotations must be natural, the dice will rotate by shuffling the used mobile phone; the level of game difficulty will increase as the level increases marked by the increasing number of dice number.

The system architecture of both these android based games is described in Fig 3.

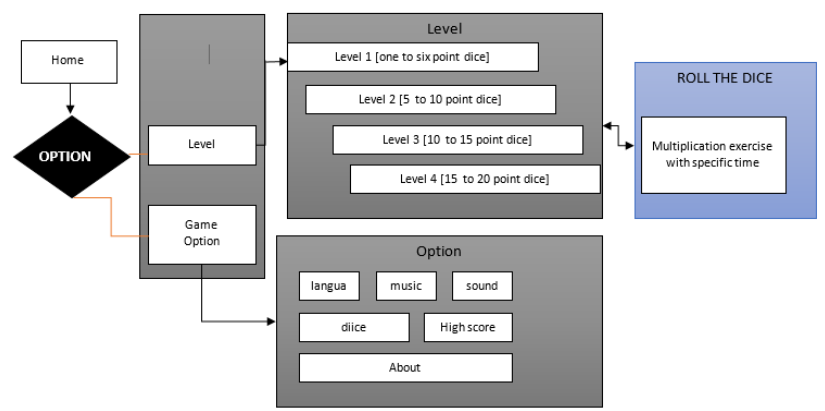

Fig 3: BeeM Math $X$ and Bingo Math $X$ system architecture

The requirements of the implementation environment used in the development of this game are Asus computer A43SV with Core i3 processor, 4 GB RAM. While the required software is Unity Game Engine; Mono Develop text storage; C \# Programming Language; with Adobe Illustrator and Photoshop for interface design.

The implementation process of the interface that is shown in fig. 4 and fig. 5.

\section{The Game Description}

\section{"Bingo Math X"}

- "BeeM Math X" game started with a splash screen, then enters automatically on the game's home. In the home screen there is an option button for language, sound, music, change the dice, record the highest score recordsetting. When the play logo is selected, then there will appear to the next screen, that is the level selection. Students can exit the app at any time by selecting the back button on the device multiple times.

- In the next stage, there is the identity of the game name along with the game level. The default open game level is level 1 . The next level will unlock after completing the level 1 of the game using two dice of $1,2,3,4,5,6$ numbers. Level 2 is a game using two dice of 5,6,7,8,9,10 number. Level 3 game using two dice of $10,11,12,13,14,15$ numbers and level 4 that is game by using two dice of $15,16,17,18,19,20$ numbers.

- The students will have 5 lives, and there are 36 boxes which are the chance of multiplying the two numbers on the dice. If students are ready to play, students must choose to roll the dice and then shake the dice until it stops and the dice shows two numbers of multiplication. The students are given 10 seconds to answer the question in the provided box. The faster, the more points will achieve if the answer incorrect. When students answer correctly, eg $6 * 5$ players press 3 and 0 (means true). Then the game board will appear, and the number 30 on the board will change its color. The board will not change color if the student has the wrong answer but will reduce the number of life. The game will continue until the student can change all the board games and unlock to enter the next level. 

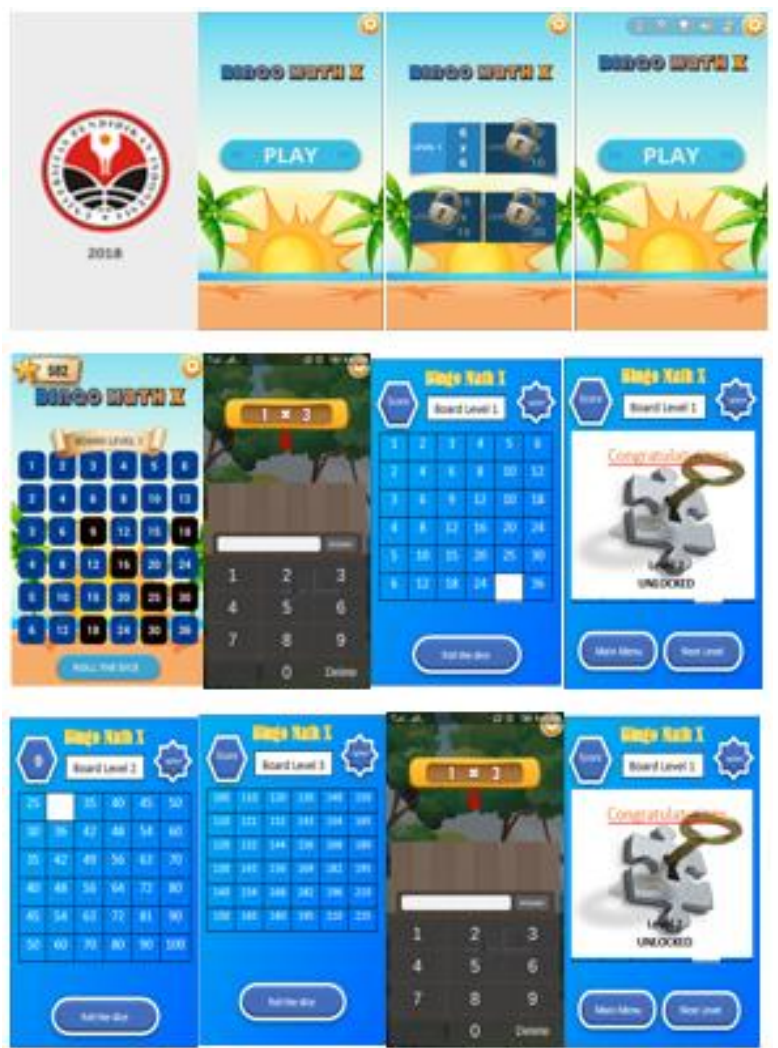

Fig. 4: User Interface Implementation of "Bingo Math X"

\section{"Beem Math X"}

- Just like "Bingo Math X", "BeeM Math X" game starts with a splash screen, then enters automatically on the game's homepage etc.

- The level of the game in this game is also as same as "Bingo Math X".

- $\quad$ The next step students will have 5 lives, and there are 19 hexagons (players must first choose one hexagon to activate to roll/shake the dice). If the player has not selected one hexagon, the dice roll button is off. When the dice roll button is pressed it will appear dice that rolls with natural movement and supportive voice. When the dice have stopped spinning, a 0-9 board will appear within 10 seconds and vanish if it has passed from the specified time. The faster, the more points will achieve if the answer incorrect. If the student answer is true then the selected hexagon will be the highlight. But if the student answer is wrong, then the life will be reduced one and the selected hexagon will be crossed (failed)

- This level will end when all hexagons are selected. The score will be calculated based on the correct answer with the student's time, and the number of lines formed by 3 hexagons on the field (1 line is worth 10). As a reward, their life will be increased and level 2 will be unlocked The game on the next level is the same as on level 1 with different dice numbers.
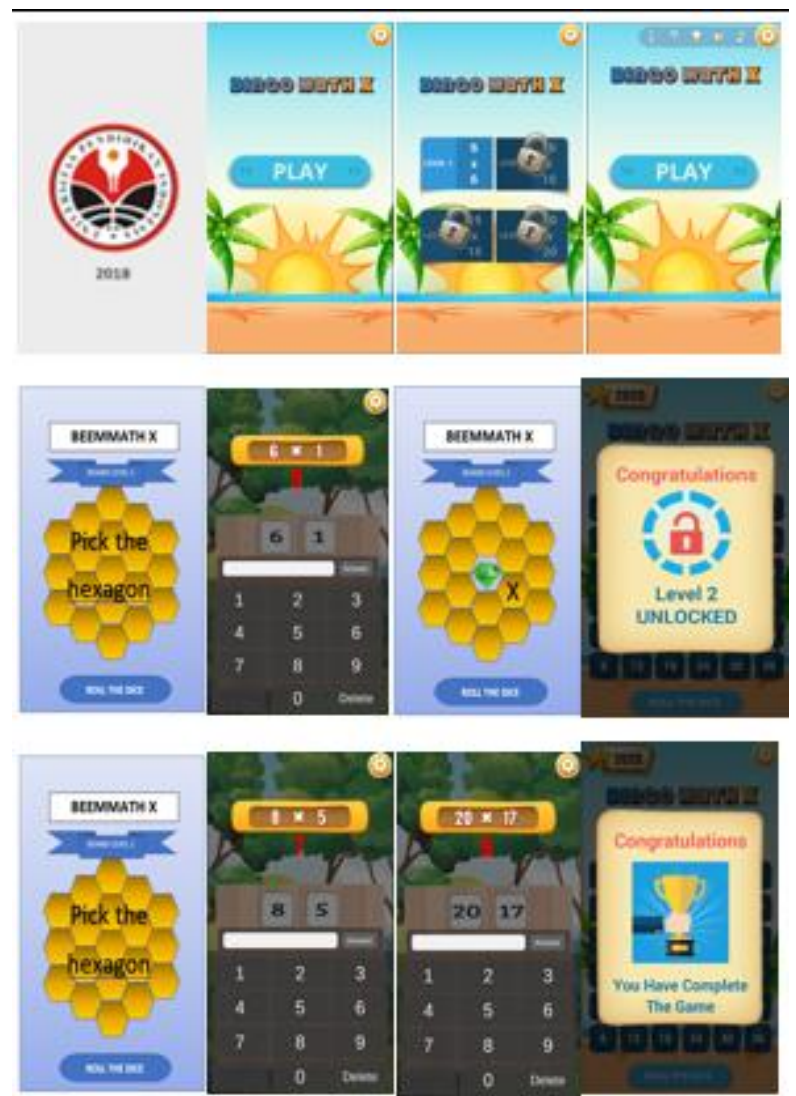

Fig. 5: User Interface Implementation of "Beem Math X"

After analyzing, designing and coding in an iterative implementation environment, final testing is done by reference to software testing standards according to ISO 25010. Based on [19] there are several characteristics in software testing including functional suitability, performance efficiency, compatibility, usability, reliability, security, maintainability, and portability and shown in fig. 6.

Functional testing is performed with black box testing that attempts to find errors in the following categories: 1) incorrect or missing functions; 2) interface error; 3 ) errors in data structures or external database access; 4) behavior or performance error; and 5) initialization and termination error [17]. Based on the test results, it is found that the system built $100 \%$ successful or in accordance with the specification of expected requirements.

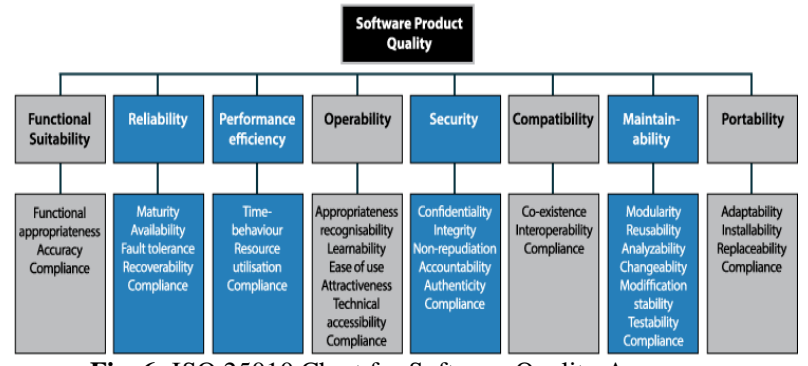

Fig. 6: ISO 25010 Chart for Software Quality Assurance

Testing is also performed on compatibility -related systems. Both of these types of tests are considered to be factors that should be prioritized in system testing as in [20] prioritizes correctness and usability. However, we recommend that complete testing of the mobile app be carried out includes: functional testing, compatibility testing, usability testing, and performance testing [21].

Compatibility testing performed by installing the system on Android devices with Lollipop to Oreo operating systems. The compatibility results of game testing on some device types shown in table 1 . 


$\left.\begin{array}{|l|l|l|l|}\hline \text { Smartphone Type } & \begin{array}{l}\text { Operating } \\ \text { system }\end{array} & \begin{array}{l}\text { Installation } \\ \text { Process }\end{array} & \begin{array}{l}\text { Application } \\ \text { Process }\end{array} \\ \hline \text { Redmi Note 4 } & \text { Marshmallow } & \text { Successful } & \begin{array}{l}\text { Successful, no } \\ \text { error }\end{array} \\ \hline \begin{array}{l}\text { Hisense Smartfren } \\ \text { Andromax R }\end{array} & \text { Nougat } & \text { Successful } & \begin{array}{l}\text { Successful, no } \\ \text { error }\end{array} \\ \hline \text { Lenovo A 6010 } & \text { Lollipop } & \text { Successful } & \begin{array}{l}\text { Successful, no } \\ \text { error }\end{array} \\ \hline \begin{array}{l}\text { Samsung Galaxy } \\ \text { A7 }\end{array} & \text { Oreo } & \text { Successful } & \begin{array}{l}\text { Successful, no } \\ \text { error }\end{array}\end{array}\right]$

As shown in table 1, it can be concluded that $100 \%$ both game was compatible with all the test device with kind of Android operating system.

\section{Conclusion}

The development of digital dice that is implemented in "Bingo Math X and Beem Math X" games is an effort to make students feel happy and engaged emotionally [22] in learning mathematics. Students will be involved and have different experiences, because the game is determined by the students themselves, based on the results of digital dice shuffle. The digital dice will determine the questions that students have to answer. Different experiences will provide the element of joyful learning in this gamification [23] because students not only tap the screen just like other android based games.

This game developed with SDLC method and the testing result shows that the dice is rolling naturally with a supportive sound. Other functions such as user interface and algorithms are successfully run in some types of Android devices used as the test tools. Thus based on functionality, the digital dice games can be used in math education through gamification. Future research and consideration are related to usability and performance efficiency test and the effect of gamification using this digital dice.

\section{Acknowledgement}

This research was performed in the context of the games for primary school Project, which is co-funded by KEMRISTEKDIKTI, Indonesian Ministry of Research, Technology, \& Higher Education. We thank Taufik Ridwan and the team the for their support with the materials and constructing this educational game.

\section{References}

[1] G. Smith, The Teaching of Arithmetic. J. School of Science and Mathematics, vol. 12, June 1912, pp 457-460

[2] J. Piaget. Cognitive Development in Children: Piaget Development and Learning. Part 1. J. Research In Science Teaching, vol. 2, 1964, pp. 176-186

[3] D. A. Johnson, Commercial games for arithmetic class, J. The Arithmetic Teacher, vol. 5, No. 2, 1958, pp.69-73

[4] L. Pareto, Mathematical literacy for everyone using arithmetic games. Proc. 9th Intl Conf. disability, virtual reality \& associated technologies laval, France, 10-12 Sept. 2012.

[5] E. N. Castelar, A. All, L. d Mariez, J. V. Looy, Cognitive abilities, digital games and arithmetic performance enhancement: A study comparing the effects of a math game and paper exercises. J. of Computers \& Education, Vol. 85, July 2015, pp 123-133.

[6] E. N. Castellar, J. V. Looy, A Szmalec, L. d. Marez. Improving arithmetic skills through gameplay: Assessment of the effectivenes of an educational game in terms of cognitive and affective learning outcomes. J. Information Sciences, vol. 264, 20 April 2014, pp 1931.

[7] J. C. Lester, H. A. Spires, J. L. Nietfield, J. Minogue, B. W. Mott, E. $\mathrm{V}$. Lobene, Designing game-based learning environments for elementary science education: A narrative-centered learning perspective. J. Information Sciences, vol. 264, 20 April 2014, pp 4-18.

[8] Statista, Global market share held by the leading smartphone operating systems in sales to end users from 1st quarter 2009 to $1 \mathrm{st}$ quarter 2018. Retrieve June 4th, 2018, from https://www.statista.com/statistics/266136/global-market-shareheld-by-smartphone-operating-systems/

D. S. Purdue, increasing students engagement in math with online games and elements of game theory. Proc. research council of mathematics learning, 2016, Los Angeles

F. L. Kahleel, N. S. Ashaari, T.S.M.T. Wook, A. Ismail, Gamification elements for learning applications. j, international journal on advance science engineering information technology. vol. 6 no. 6 . pp 868-874

G. Kiryakova, et al, Gamification in Education. Proceedings of 9th International Balkan Education and Science Conference, 2014

U. Faghihi, A. Brautigam, K Jorgenson, D. Martin, A Brown, E Measures, S. M. Bouchard, How gamification applies for educational purpose specially with college algebra, Proc. 5th Intl Conf. on biologically inspired cognitive architectures, Procedia computer science, vol. 41, 2014, pp. 182-187

G. Goehle, Gamification, and web-based homework, J. PRIMUS: Problems, Resources, and Issues in Mathematics Undergraduate Studies, vol. 23, No. 3, pp. 234-246

[14] H. Y. Huang \& D. Soman, A practitioners guide to the gamification of educations. research report of Rotman school of management university of Toronto

[15] R. W. Borg, \& M.D. Gall, Educational research: an introduction (7th ed., 2003, New York: Longman, Inc.

[16] Sugiyono, Quantitative research methods, qualitative and R \& D Trans.: Metode Penelitian Kuantitatif, Kualitatif dan R\&D, 2009, Bandung: Alfabeta

S. R. Pressman, Software engineering: a practitioner's approach 2010. New York: McGraw-Hill Companies, Inc.

T.V. Ark, 8 Principles of Productive Gamification, 2014, Retrieved, June 4th, 2018 from http://www.gettingsmart.com/2014/02/8principles-productive-gamification/

[19] J. P. Miguel, D. Mauricio, G. ROdriguez., A review of software quality models for the evaluation of software Products, 2014, J. international journal of software engineering \& applications, vol.5, no.6, November 2014, pp 31-54

[20] F. M. Fararit, Testing correctness and usability factor of alumni information system uin sunan kalijaga yogyakarta using mccall method. Trans. Pengujian faktor correctness dan usability sistem informasi alumni uin sunan kalijaga yogyakarta menggunakan metode mccall, Thesis: unpublished. 2015. Universitas islam negeri sunan kalijaga yogyakarta

[21] Kandasoft, Best-practices-in-mobile-quality-assurance-and-testing 2014. Retrieved june 4th 2018, from Kanda software: https://www.kandasoft.com/wp-content/uploads/2015/07/BestPractices-in-Mobile-Quality-Assurance-and-Testing.pdf

A. Bartel and G. Hagel, Engaging students with a mobile game-based learning system in university education, 2014 IEEE Global engineering education Conf., Istanbul, Turkey, pp. 957-960

[22] M. Prensky, Digital game-based learning, ACM Computers in Entertainment, vol. 1, no. 1, October 2003, Book 02 